\title{
USULAN PERBAIKAN PROSES MAINTENANCE RECORD SR DENGAN PENDEKATAN VALUE STREAM MAPPING DI PT. GMF-Aeroasia
}

\author{
Diah Septiyana ${ }^{1)}$, Indra Kurniawan ${ }^{2)}$ \\ ${ }^{1,2)}$ Program Studi Teknik Industri, Fakultas Teknik \\ Universitas Muhammadiyah Tangerang \\ Jl. Perintis Kemerdekaan I/33 Cikokol, Kota Tangerang \\ E-mail : Dee.septie@gmail.com, indrakurniawan043@gmail.com
}

\begin{abstract}
A b s tract
Kegiatan maintenance atau perawatan adalah kegiatan yang rutin dilakukan pada perusahaan MRO (Maintenance, Repair and Overhaul). Dalam proses perawatan suatu pesawat, terdapat dokumen yang dihasilkan sebagai representasi dari kualitas perawatan suatu pesawat atau disebut maintenance record. Selama proses maintenance record masih ditemui pemborosan atau waste yang menyebabkan target pengiriman dokumen melewati batas standar yaitu 3 hari. Lean manufacturing merupakan pendekatan yang bertujuan untuk meminimasi pemborosan yang terjadi pada aliran proses. Pemahaman kondisi dari proses digambarkan dalam value stream mapping untuk selanjutnya dijabarkan aktifitas yang memiliki nilai tambah dan tidak memiliki nilai tambah. Dari hasil pengukuran waktu kerja diperolah waktu baku sebesar 8781,53 menit atau 6,09 hari. Selanjutnya hasil analisis dengan current state mapping diketahui terdapat 7 proses yang tidak memberi nilai tambah dan memyebabkan keterlambatan pengiriman dokumen. Untuk lebih mengetahui faktor penyebab keterlambatan maka dibuatkan diagram fishbone. Usulan perbaikan yang diberikan untuk meminimasi waste yang terjadi diantaranya, dibuatkan check sheet penerimaan dokumen, penggabungan proses review dan completion, proses pengemasan dan pengiriman dilakukan diruang $P C$, dll. Dari hasil usulan perbaikan dan current state map yang dibuat sebelumnya maka dapat digambarkan dalam future state map yang mampu menghemat waktu sebesar 40,81\% menjadi 1200 menit atau 2,5 hari.
\end{abstract}

Key words : Maintenance Record, Waktu Baku, Value Stream Mapping, Diagram Fishbone.

\section{PENDAHULUAN}

Persaingan industri di era global saat ini meningkat sangat pesat. Persaingan ini timbul sebagai salah satu konsekuensi kemajuan ilmu pengetahuan dan teknologi. Persaingan ini menuntut sebuah industri terus mengembangkan kapabilitasnya demi memenuhi tuntutan dari pasar yang ada. Performa yang diukur berdasarkan efektivitas dan efisiensi dari alur produksi suatu perusahaan akan menunjukkan korelasi yang sebanding dengan output perusahaan yang direpresentasikan dengan bentuk akhir berupa tingkat kepuasan pelanggan PT. GMF-Aeroasia adalah salah satu perusahaan yang bergerak dibidang penerbangan khususnya pada perawatan pesawat (maintenance, repair and overhaul). Saat ini PT. GMF-Aeroasia diakui sebagai salah satu fasilitas terbaik dan terbesar dalam pemeliharaan, perbaikan dan overhaul pesawat dikawasannya.

Dokumen perawatan pesawat (maintenance record) merupakan catatan yang timbul saat dilakukan maintenance pada pesawat, engine dan komponen pesawat yang menjadi catatan historical tentang perawatan baik minor maupun major dan yang bersifat continuing atau terminate. Maintenance record berisi lembar kerja (Job Card dan MDR) yang telah dikerjakan oleh mekanik atau teknisi pesawat. Selain itu berisi juga laporan hasil inspeksi, jam terbang pesawat, perbaikan dan penggantian komponen, dll. Fungsi maintenance record sendiri tidak lain sebagai controlling maintenance program dan reliability program. Yang berhak mengeluarkan maintenance 
record adalah semua pelaku maintenance baik pesawat maupun komponen yang dalam hal ini dikelola dan dikontrol oleh unit Maintenance Record Management (TBS-6).

Dalam proses maintenance record, standar lead time atau TAT yang ditetapkan perusahaan adalah 3 hari untuk inspeksi pesawat SR (squawk request). Tetapi dalam pelaksanaannya masih banyak pengiriman dokumen ke pelanggan yang melewati standar atau lebih dari 3 hari.

Tabel 1 Jumlah SR Delayed dan Ontime

\begin{tabular}{|l|r|r|r|}
\hline Bulan & Jumlah & Delayed & Ontime \\
\hline Januari & 96 & 71 & 25 \\
\hline Februari & 121 & 68 & 53 \\
\hline Maret & 102 & 52 & 50 \\
\hline April & 71 & 62 & 9 \\
\hline Mei & 114 & 57 & 57 \\
\hline Juni & 82 & 55 & 27 \\
\hline Jumlah & 586 & 365 & 221 \\
\hline
\end{tabular}

Berdasarkan tabel 1.1 yang diperoleh dari sistem kontrol TBS-6 periode Januari hingga Juni 2017, terdapat 586 maintenance record inspeksi SR yang telah dikirim ke pelanggan dan 365 diantaranya mengalami keterlambatan pengiriman. Persentase keterlambatan pengiriman dokumen SR periode bulan Januari hingga Juni 2017 mencapai 62\% dikarenakan pengiriman dokumen melewati batas standar 3 hari. Hal ini menjadi permasalahan yang perlu mendapat penanganan lebih mendetail. Oleh karena itu diperlukan analisis hasil pencapaian Turn Around Time antara target yang ingin dicapai dengan realisasi.

\section{METODE PENELITIAN}

Pada metode penelitian menggunakan 5 tahapan yaitu: perhitungan waktu baku, diagram SIPOC, current state mapping, diagram fishbone dan future state mapping. Tahapan penelitian bisa dilihat pada gambar 1 .

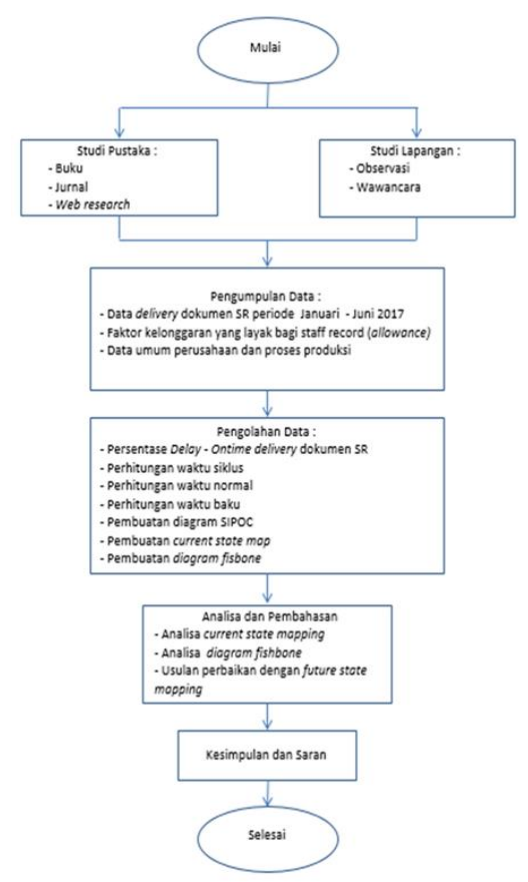

Gambar 1. Diagram Alur penelitian 


\section{HASIL DAN PEMBAHASAN}

\section{A. Perhitungan Waktu Baku}

1. Menghitung Waktu Siklus

Berdasarkan tabel diatas perhitungan waktu siklus dapat diperoleh dengan rumus:

$W s=\frac{\sum x i}{\mathrm{n}}$

$W s=\frac{3399}{586}=5,80$ hari $=139,2$ jam $=8352$ menit

\section{Menghitung Waktu Normal}

Nilai performa rating berikut ini diambil berdasarkan pada hasil pengamatan pada saat unit maintenance record bekerja. Pengambilan penilaian merupakan penilaian secara subjektif namun disesuaikan dengan kondisi yang sesungguhnya. Performance Rating menurut Westinghouse System:

Performa Rating $=0,08$

Maka: $\mathrm{P}=(1-0,08)=0,92$

$\mathbf{W n}=\mathrm{Ws} \times \mathrm{p}$

$=$ Waktu siklus $\mathrm{x}$ performa rating $(\mathrm{p}=0,92)$

$=8352 \times 0,92=7683,84$ menit $=128,06$ jam $=5,33$ hari

\section{Menghitung Waktu Baku (Waktu Standar)}

Asumsi kelonggaran waktu yang dilakukan pekerja adalah 60 menit. Sehingga perhitungan Allowance untuk jam kerja 8 jam adalah:

$$
\begin{aligned}
& \frac{60}{480}=0,125 \times 100 \%=12,5 \% \\
& \boldsymbol{W} \boldsymbol{b}=\boldsymbol{W n} \frac{\mathbf{1 0 0} \%}{\mathbf{1 0 0} \%-\% \text { allowance }} \\
& W b=7683,84 \frac{100 \%}{100 \%-12,5 \%}=8781,53 \text { menit }=146,35 \mathrm{Jam}=6,09 \text { Hari }
\end{aligned}
$$

Jadi waktu baku yang diperoleh untuk proses maintenance record satu pesawat SR pada periode bulan Januari hingga Juni 2017 berdasarkan perhitungan diatas adalah 6,09 hari.

\section{B. Diagram SIPOC}

Diagram SIPOC menggambarkan informasi mengenai Supplier, Input, Process, Output dan Customer yang terlibat dalam proses maintenance record SR. Diagram SIPOC untuk proses maintenance record $S R$ dapat dilihat pada gambar dibawah ini :

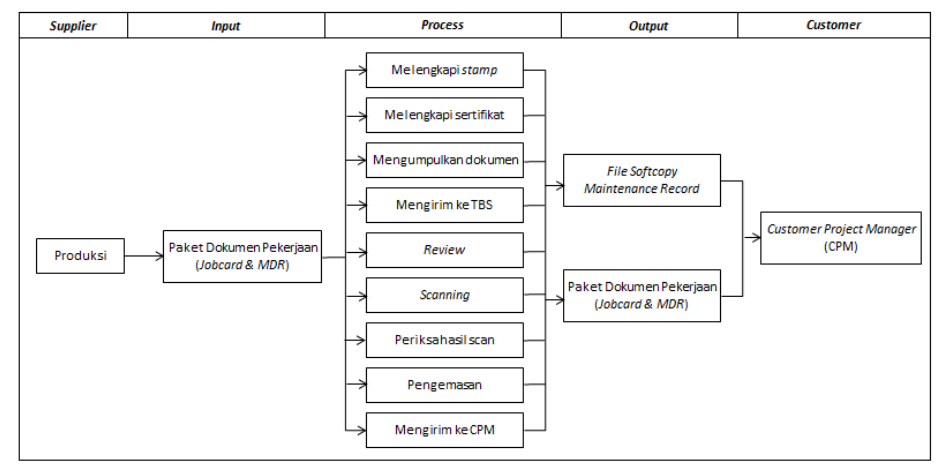

Gambar 2. Diagram SIPOC Proses Maintenance Record SR 
Elemen-elemen yang digunakan dalam diagram ini yang telah ditunjukan pada gambar diatas adalah sebagai berikut:

1. Supplier: Produksi

2. Input: Paket dokumen pekerjaan (Jobcard \& MDR)

3. Process: Melengkapi stamp, melengkapi sertifikat, mengumpulkan dokumen, mengirim ke TBS, review, scanning, periksa hasil scan, pengemasan dan mengirim ke CPM.

4. Output: File softcopy maintenance record dan paket dokumen pekerjaan (Jobcard \& MDR)

5. Customer: Customer Project Manager (CPM)

Selanjutnya dari diagram SIPOC dilakukan penggambaran value stream mapping current state yang berguna untuk memetakan aliran proses yang terjadi saat ini.

\section{Current State Mapping}

Pada pembuatan current state map dilakukan observasi secara langsung dan dilakukan wawancara pada PC, staff material, staff record, supervisor, dan pihak-pihak yang terkait dengan proses maintenance record. Cara pengambilan data ada yang melalui pengukuran langsung dan ada yang tidak langsung. Pengukuran langsung diambil dengan cara pengamatan dan pengukuran waktu mulai dari produksi hingga dikirim ke customer project manager (CPM). Pengukuran tidak langsung waktu yang diperoleh melalui hasil wawancara dengan personil yang berkaitan dengan proses tersebut.

Tabel 2 Aktifitas Value Added (VA) dan Non Value Added (NVA)

\begin{tabular}{|c|c|c|c|c|}
\hline No & Aktifitas & $\begin{array}{c}\text { Value Added } \\
\text { (VA) }\end{array}$ & $\begin{array}{c}\text { Non Value Added } \\
\text { (NVA) }\end{array}$ & Waktu (Menit) \\
\hline 1 & Review \& Released & VA & & 240 \\
\hline 2 & Menunggu & & NVA & 60 \\
\hline 3 & Menerima Dokumen & & NVA & 60 \\
\hline 4 & Melengkapi stamp & & NVA & 1440 \\
\hline 5 & Melengkapi sertifikat & & NVA & 180 \\
\hline 6 & $\begin{array}{l}\text { Mengumpulkan } \\
\text { dokumen }\end{array}$ & VA & & 420 \\
\hline 7 & Mengirim ke TBS & & NVA & 60 \\
\hline 8 & Menunggu & & NVA & 60 \\
\hline 9 & Menerima Dokumen & & NVA & 30 \\
\hline 10 & Review & VA & & 180 \\
\hline 11 & Scanning & VA & & 60 \\
\hline 12 & Periksa hasil scan & VA & & 60 \\
\hline 13 & Pengemasan & VA & & 30 \\
\hline \multirow[t]{2}{*}{14} & Mengirim ke CPM & VA & & 60 \\
\hline & Total & 1050 & 1890 & 2940 \\
\hline
\end{tabular}




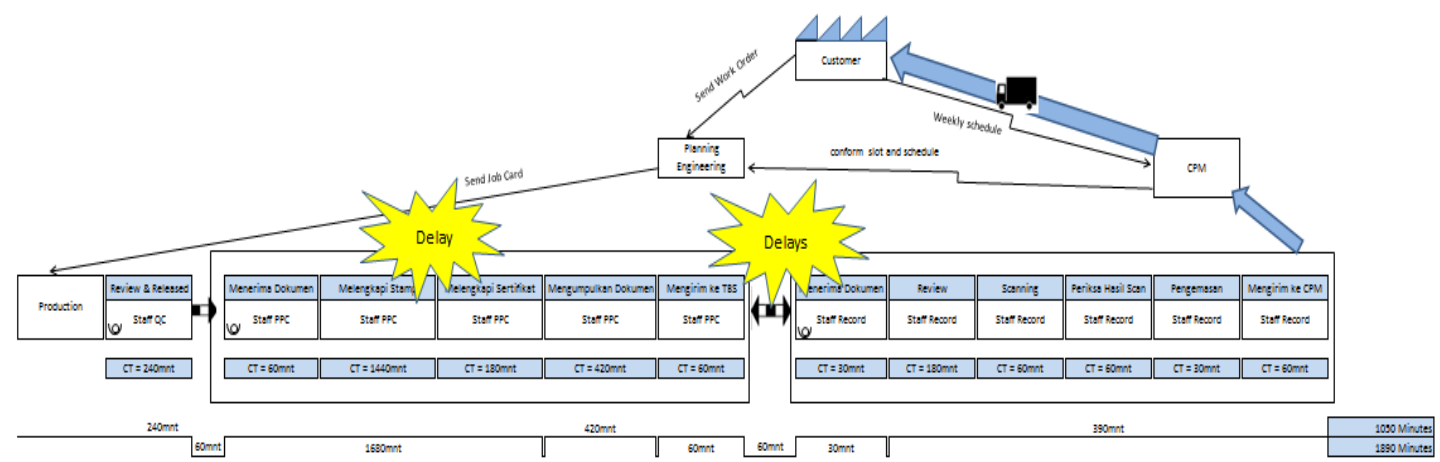

Gambar 3 Current State Mapping Maintenance SR

Untuk mengetahui alur proses maintenance record digunakan metode value stream mapping. Setelah digambarkan dengan current state map maka pemeteaan tersebut akan dijadikan acuan untuk mengidentifikasi pemborosan (waste) yang terjadi sepanjang value stream seperti terlihat pada gambar 3. Dari gambar 3 diketahui proses yang memakan waktu paling lama adalah melengkapi stamp, paraf dan tanggal mencapai 1440 menit atau 24 jam. Hal ini terjadi karena untuk melengkapi stamp dan paraf yang terlewat, PC baru dapat melengkapi esoknya sampai mekanik tersebut masuk kembali dan terdapat pengelompokan 2 bagian kerja yaitu unit PC dan unit TBS-6. PC harus menyerahkan dokumen SR ke TBS untuk di review dan bila ada kekurangan staff record akan mengembalikan lagi dokumen tersebut ke PC untuk dilengkapi. Hal ini membuat proses menjadi tidak efisien dan menyebabkan pengulangan proses kerja (rework) sehingga dokumen menjadi terlambat dikirim ke pelanggan.

Pada tabel 2 terdapat 7 proses yang termasuk value added dan 7 proses non value added. Untuk mempercepat proses maintenance record diperlukan usulan perbaikan untuk meminimasi waste yang ada dan mengurangi lead time dari proses non value added agar pengiriman dokumen menjadi lebih cepat.

\section{Diagram Fishbone}

Melalui hasil pengukuran waktu dan proses pengamatan yang dilakukan, terdapat beberapa faktor yang mengakibatkan waktu dalam proses maintenance record menjadi lama. Dampak dari lamanya proses maintenance record adalah terlambatnya pengiriman dokumen ke pelanggan (customer) dan menurunya nilai KPI dari unit maintenance record itu sendiri. Adapun identifikasi faktor penyebab keterlambatan pengiriman proses maintenance record $S R$ dapat dianalisa menggunakan fishbone diagram seperti terlihat pada gambar dibawah ini :

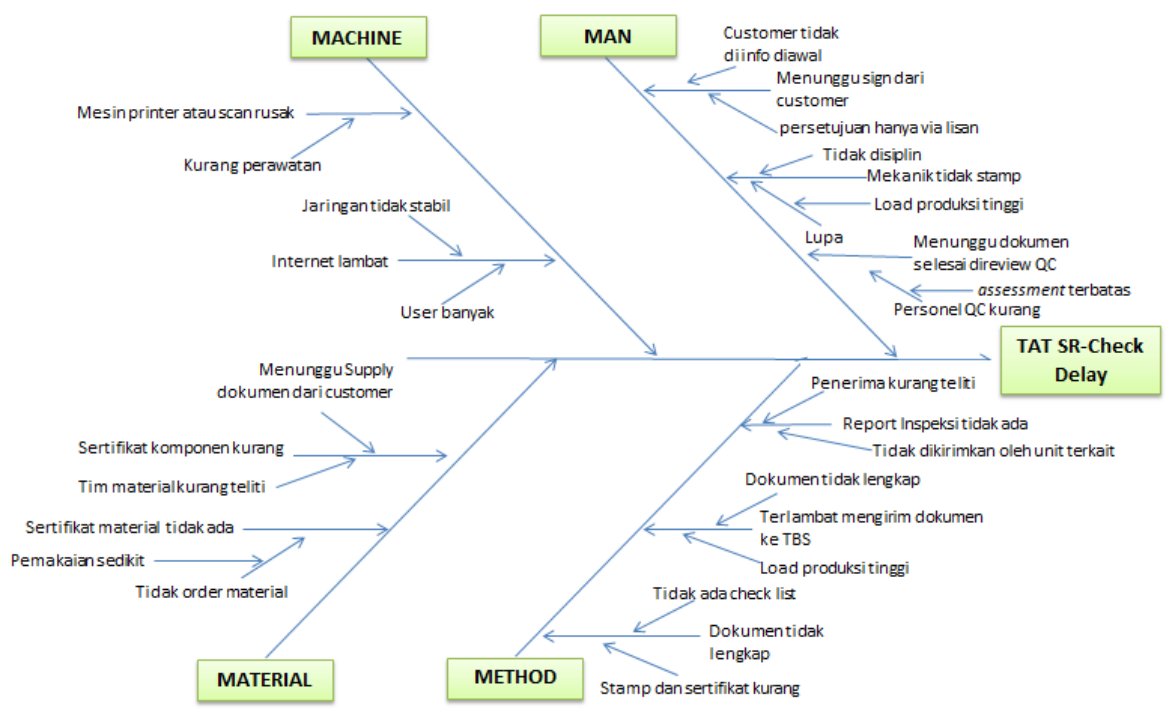

Gambar 3. Diagram Fishbone TAT SR Delay 
Berdasarkan gambar 3 dapat dilihat faktor apa saja yang mengakibatkan waktu yang dibutuhkan untuk proses maintenance record $S R$ menjadi lama dan terlambat. Untuk waste yang ditemukan tentu harus memiliki solusi atau penyelesaian. Maka dari itu, akan diberikan usulan atau solusi untuk mengurangi atau bahkan dapat menghilangkan waste tersebut. Solusi yang diberikan adalah :

Tabel 3. Rencana Penanggulangan Keterlambatan TAT SR

\begin{tabular}{|c|c|c|}
\hline $\begin{array}{c}\text { Faktor Yang } \\
\text { Diamati }\end{array}$ & Masalah Yang Terjadi & Usulan Perbaikan \\
\hline \multirow{3}{*}{ Man } & $\begin{array}{l}\text { a. Menunggu dokumen selesai } \\
\text { di review oleh QC atau } \\
\text { releaseman }\end{array}$ & $\begin{array}{l}\text {-Melakukan assessment baru untuk menambah } \\
\text { personel QC dan releaseman }\end{array}$ \\
\hline & b. Mekanik tidak stamp. & $\begin{array}{l}\text {-Memberikan pengarahan prosedur kerja pada } \\
\text { setiap briefing sebelum mulai bekerja. } \\
\text {-Memberikan sanksi administrative kepada } \\
\text { mekanik yang tidak stamp. }\end{array}$ \\
\hline & $\begin{array}{l}\text { c. Menunggu sign dari } \\
\text { customer }\end{array}$ & $\begin{array}{l}\text {-Memberikan informasi dari awal mengenai } \\
\text { prosedur kelengkapan dokumen. } \\
\text {-Tidak menunda pekerjaan selesai untuk meminta } \\
\text { sign dari customer. }\end{array}$ \\
\hline \multirow[t]{3}{*}{ Method } & a. Report inspeksi tidak ada. & $\begin{array}{l}\text {-Hasil review yang dilakukan oleh staff record bila } \\
\text { ada kekurangan, PC dapat langsung melengkapi } \\
\text { kekurangan dokumen tersebut sehingga proses } \\
\text { review dan completion dapat dikerjakan beriringan } \\
\text { dalam satu waktu. } \\
\text {-Dilakukan pengontrolan oleh PC untuk } \\
\text { menanyakan report hasil inspeksi jika ada } \\
\text { pekerjaan inspeksi khusus. }\end{array}$ \\
\hline & $\begin{array}{l}\text { b. Terlambat mengirim } \\
\text { dokumen ke TBS }\end{array}$ & $\begin{array}{l}\text {-Memberi tahu staff record agar dapat membantu } \\
\text { mengambil dokumen yang sudah komplit ketika } \\
\text { load produksi sedang tinggi. } \\
\text {-Untuk mempercepat proses review, staff record } \\
\text { dapat langsung mereview dokumen setelah } \\
\text { dikroscek oleh QC tanpa harus menunggu dokumen } \\
\text { dikirim oleh PC. }\end{array}$ \\
\hline & c. Dokumen tidak lengkap & $\begin{array}{l}\text { - Dibuatkan check sheet penerimaan dokumen dari } \\
\text { PPC atau QC, diharapkan dengan menggunakan } \\
\text { check sheet dokumen yang dikirim dari QC ataupun } \\
\text { dari PC sudah sesuai dengan daftar yang ada pada } \\
\text { check sheet tersebut. } \\
\text {-Dilakukan pengontrolan dokumen setiap pekerjaan } \\
\text { telah selesai. }\end{array}$ \\
\hline \multirow[b]{2}{*}{ Machine } & $\begin{array}{l}\text { a. Mesin printer atau scan } \\
\text { rusak. }\end{array}$ & $\begin{array}{l}\text { Meminta provider mesin printer agar melakukan } \\
\text { pengecekan secara berkala kondisi tinta dan mesin. }\end{array}$ \\
\hline & b. Internet lambat & $\begin{array}{l}\text {-Menambah bandwitch internet pada jaringan yang } \\
\text { digunakan. } \\
\text {-Melakukan maintenance jaringan secara berkala. }\end{array}$ \\
\hline \multirow[t]{2}{*}{ Material } & $\begin{array}{l}\text { a. Sertifikat komponen } \\
\text { kurang. }\end{array}$ & $\begin{array}{l}\text {-Unit PPC sebaiknya langsung meminta customer } \\
\text { melengkapi dokumen pada saat pesawat masuk. } \\
\text {-Personel material harus selalu menduplikat } \\
\text { sertifikat yang baru datang atau baru dibuat. }\end{array}$ \\
\hline & b. Sertifikat material tidak ada. & $\begin{array}{l}\text { Setiap penggunaan material harus dilakukan order } \\
\text { meskipun hanya sedikit. }\end{array}$ \\
\hline
\end{tabular}




\section{E. Future State Mapping}

Pembuatan future state map mengacu pada current state map yang dibuat sebelumnya dan berdasarkan usulan yang telah diberikan. Pada future state maintenance record dibuat dengan menggabungkan proses yang dapat dikerjakan beriringan, simpifikasi pekerjaan dan menghilangkan beberapa proses yang tidak memberi nilai tambah (non value added). Proses yang dihilangkan diantaranya: received document, completion stamp, sign and date, completion certificate, send to TBS.

Tabel 4 Tabel aktifitas dan Waktu Proses Future State Map

\begin{tabular}{|c|c|c|c|c|c|}
\hline \multirow{2}{*}{ No } & \multicolumn{2}{|c|}{ Current State Map } & \multicolumn{2}{|c|}{ Future State Map } & \multirow{2}{*}{ Ket. } \\
\hline & Aktifitas & $\begin{array}{c}\text { Waktu } \\
\text { (Menit) }\end{array}$ & Aktifitas & $\begin{array}{c}\text { Waktu } \\
\text { (Menit) }\end{array}$ & \\
\hline 1 & Review \& Released & 240 & Review \& Released & 240 & \\
\hline 2 & Menunggu & 60 & Menunggu & 60 & \\
\hline 3 & Menerima Dokumen & 60 & $\begin{array}{l}\text { Menerima, Memeriksa } \\
\text { Dokumen dan } \\
\text { Melengkapi stamp }\end{array}$ & 240 & \\
\hline 4 & Melengkapi stamp & 1440 & - & - & \\
\hline 5 & Melengkapi sertifikat & 180 & - & - & \\
\hline 6 & Mengumpulkan dokumen & 420 & $\begin{array}{l}\text { Melengkapi sertifikat } \\
\text { dan mengumpulkan } \\
\text { dokumen }\end{array}$ & 480 & \\
\hline 7 & Mengirim ke TBS & 60 & - & - & \\
\hline 8 & Menunggu & 60 & - & - & \\
\hline 9 & Menerima Dokumen & 30 & - & - & \\
\hline 10 & Review & 180 & - & - & $\begin{array}{l}\text { Dimulai } \\
\text { setelah } \\
\text { menerima } \\
\text { dokumen } \\
\text { dari QC }\end{array}$ \\
\hline 11 & Scanning & 60 & Scanning & 60 & \\
\hline 12 & Periksa hasil scan & 60 & Periksa hasil scan & 60 & \\
\hline 13 & Pengemasan & 30 & Pengemasan & 30 & \\
\hline 14 & Mengirim ke CPM & 60 & Mengirim ke CPM & 30 & $\begin{array}{l}\text { Dilakukan } \\
\text { diruang PC }\end{array}$ \\
\hline & Total & 2940 & & 1200 & \\
\hline
\end{tabular}




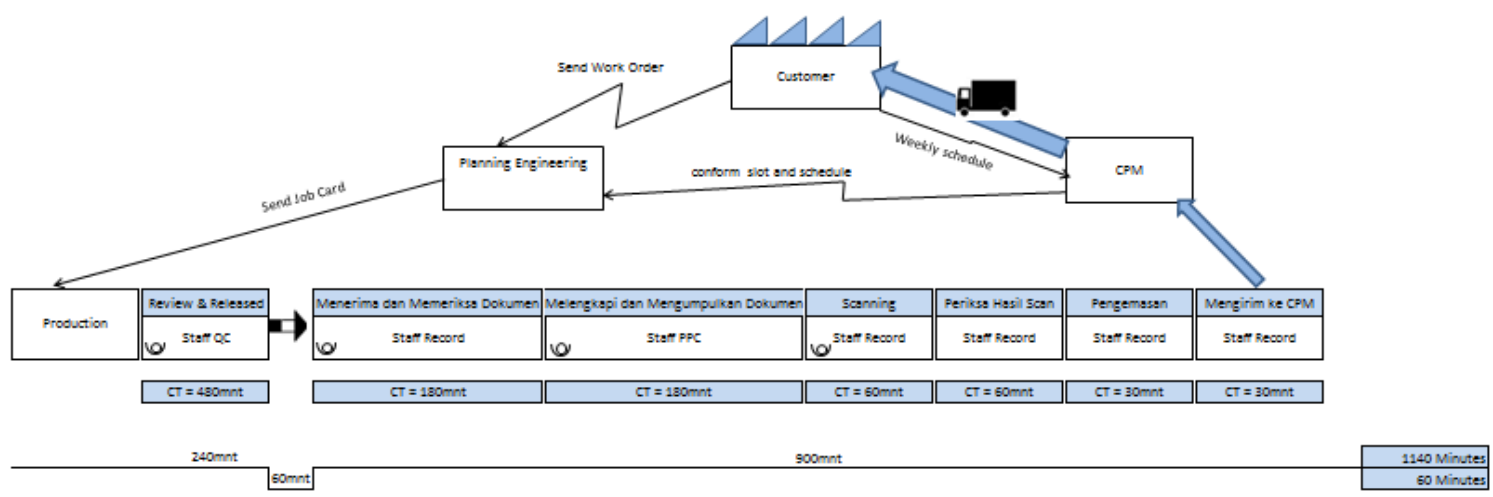

Gambar 4 Futue State Mapping Maintenance SR

Dari future state map yang sudah dibuat, dapat dilihat bahwa ada perbedaan waktu yang dihasilkan. Proses yang terjadi menjadi lebih cepat atau menghemat waktu sebanyak $40,81 \%$.

\section{KESIMPULAN DAN SARAN}

\section{Kesimpulan}

Berdasarkan hasil dari pengumpulan dan pengolahan data serta analisa yang dilakukan, maka diambil kesimpulan sebagai berikut :

1. Keterlambatan (delay) TAT yang terjadi pada pengiriman dokumen untuk inspeksi pesawat SR periode Januari hingga Juni 2017 adalah sebesar 62\%. Dengan breakdown delay terbanyak terjadi pada bulan Januari sebanyak 71 pengiriman dokumen SR delay dan 25 SR ontime.

2. Waktu baku yang diperoleh untuk proses maintenance record inspeksi pesawat SR periode bulan Januari hingga Juni 2017 adalah 8781,53 menit atau 6,09 hari.

3. Berdasarkan grafik current state mapping diketahui terdapat 7 proses yang masuk kategori value added, dan 7 proses non value added. Waste yang menyebabkan TAT SR mengalami keterlambatan (delay) antara lain adalah:

a. Man yang meliputi

- Menunggu dokumen selesai di review QC

- Mekanik tidak stamp

- Menunggu sign dari customer

b. Method yang meliputi

- Report inspeksi tidak ada,

- Terlambat mengirim dokumen ke TBS

- Dokumen tidak lengkap

c. Machine yang meliputi

- Mesin printer atau scan rusak,

- Internet lambat.

d. Material yang meliputi

- Sertifikat komponen kurang,

- Sertifikat material tidak ada.

4. Usulan perbaikan diantaranya adalah, penambahan personel QC dan releaseman, dibuatkan check list penerimaan dokumen, proses review dan record dokumen dilakukan diruang PC, pengiriman dokumen ke CPM langsung pada saat proses maintenance record telah selesai. Pembuatan future state map value stream mapping berdasarkan pengurangan proses dan 
usulan yang telah diberikan untuk mengurangi total lead time pengiriman dokumen. Total lead time pada maintenance record SR berkurang sebesar $40,81 \%$.

\section{Saran}

Rekomendasi yang diberikan kepada PT. GMF-Aeroasia untuk mengatasi faktor penyebab dari permasalahan diatas adalah :

- Melakukan pengawasan bersama dan meningkatkan kualitas hasil kerja sesuai prosedur yang berlaku.

- Mengupayakan perbaikan proses terkait dengan komunikasi antar bagian, prosedur teknis dalam proses,seperti, standar pengisian dokumen, proses record dan aktivitas pendukung proses lainya.

- Memfokuskan untuk menjaga kualitas dan kepuasan customer dalam melakukan perawatan pesawat di PT. GMF-Aeroasia sesuai dengan agreement yang telah disepakati.

- Melakukan evaluasi dalam setiap pengiriman yang mengalami keterlambatan dan dilakukan tindakap preventif agar tidak terulang.

- Melakukan assessment dan penambahan personel releaseman dan QC pada setiap capability pesawat yang dikerjakan oleh PT. GMF-Aeroasia.

\section{DAFTAR PUSTAKA}

Adrianto, Wahyu \& Kholil, M., (2015), Analisa Penerapan Lean Production Process Untuk Mengurangi Lead Time Process Perawatan Engine (Studi Kasus PT.GMF Aeroasia), Jurnal Optimasi Sistem Industri, Vol. 14, No. 2, Oktober 2015, pp. 299-309

Alpasa, Fijar \& Fitria, L., (2014), Penerapan Konsep Lean Service dan DMAIC Untuk Mengurangi Waktu Tunggu Pelayanan, Reka Integra, Vol. 02, No. 03, Juli 2014, pp. 108-117

Azis, Damar \& Susanto, N., (2016), Analisis Turn Arround Time (TAT) Pada Proses Pooling Komponen Pesawat: Studi Kasus Keterlambatan Pengembalian Komponen Pesawat CRJ 1000 Nextgen di PT. GAA, Jurnal Teknik Industri, Vol. XI, No. 1, Januari 2016, pp. $21-26$.

Barnes, R.M. (1990). Motion and Time Study, Design and Measurement of Work. New York: John Willey \& Sons

Caesar, Yosua \& Noya, S., (2014), Optimasi Lini Produksi Dengan Value Stream Mapping dan Value Stream Analysis Tools, Jurnal Ilmiah Teknik Industri, Vol. 13, No. 2, Desember 2014, pp. 125-133.

Gaspersz, Vincent. (2007). Organizational Excellence Model Strategik Menuju World Class Quality Company. Jakarta: Penerbit Gramedia Pustaka Utama.

Ishikawa, K. (1968). Guide to Quality Control. Tokyo: JUSE

Muflihah, Nur., (2017), Implementasi Lean Manufacture Dengan Metode VSM Untuk Mengurangi Waste Pada Proses Produksi Kapal (Studi Kasus PT. PAL Divisi Kaprang), Jurnal Reaktom, Vol. 02, No. 01, 2017, pp. 17-21

Prayogo, Thomas \& Octavia, T., (2013), Identifikasi Waste Dengan Menggunakan Value Stream Mapping di Gudang PT.XYZ, Jurnal Titra, Vol. 1, No. 2, Juli 2013, pp. 119-126

Rinawati, Dyah Ika, Puspitasari, D \& Muljadi, F., (2012), Penentuan Waktu Standar dan Jumlah Tenaga Kerja Optimal Pada Produksi Batik Cap: Studi Kasus IKM Batik Saud Effendy, Laweyan, Vol. VII No. 3, September 2012, pp. 143 - 150

Salamah, Goldie \& Witantyo., (2012), Minimasi Waste (Pemborosan) Menggunakan Value Stream Analysis Tool Untuk Meningkatkan Efisiensi Waktu Produksi, Jurnal Teknik Pomits ， Vol. 1, No. 1, 2012, pp. 1-6. 
Shodiq, Muhammad \& Haryono., (2015), Analisis Penerapan Lean Manufacturing Untuk Menghilangkan Pemborosan di Lini Produksi PT Adi Satria Abadi, Jurnal Rekayasa Sistem Industri,Vol. 4, No. 1, 2015, pp. 47-54

Sutalaksana, Iftikar. (1979). Teknik Tata Cara Kerja. Bandung: ITB.

Wignjosoebroto, Sritomo. (1995). Ergonomi, Studi Gerak dan Waktu. Jakarta: Guna Widya. 